\title{
Digital asset management, media asset management, and content management: From confusion to clarity
}

\author{
Skiff Wager \\ has extensive experience in the news, print, music, and cable markets for corporations like Xerox, Universal, Scripps Networks, and \\ others. He was an integral part of the global roll-out of an EDS/Xerox engagement, held the Vice President of eCAT (e-Commerce and \\ Advanced Technology) responsibility at Universal Studios, and was fortunate to be a part of his fourth launch of an asset management \\ initiative at EW Scripps (HGTV, Fine Living, Do-it-Yourself-Network, and Fine Living). Skiff has 26 years of IT experience and provides a \\ wide array of expertise in business and solutions architecture.
}

Keywords: digital asset management, media asset management, content management, financial strategy, project development, "ingest, manage, and distribute"

\begin{abstract}
Asset management strategies are increasingly being adopted by businesses and individuals who want to manage information efficiently in today's digital age. This paper discusses the different approaches on offer, covering digital asset management, media asset management, and content management. It outlines the criteria that organizations need to consider before they can select and implement the appropriate asset strategy. This paper touches briefly on the benefits that a well-structured DAM strategy can bring and what to consider during the business process.
\end{abstract}

\section{DEFINING ASSET MANAGEMENT}

Asset management over the years has been discussed at many different levels and is used loosely by individuals and businesses trying to describe the need to manage information in a digital age. From plain asset management to digital asset management to media asset management to content management, they all seem to be attempting to describe the same thing. However, each one of these labels actually reflects a different aspect of managing information. Depending upon the approach, an organization may determine what best suits its current cultural, environmental, and financial state. The following definition holds true:

\footnotetext{
Digital asset management is a business strategy to increase revenues while reducing workflow and process cycle times.
}

Digital asset management (DAM) may focus on the electronic management of any form of a digitally stored piece of information. Digital asset management is certainly strategic. Media asset management (MAM) will focus on media types (audio, video, imagery, etc), either digital or not (eg tape). MAM may be strategic on its own but is almost always tactical. Both digital and media asset management primarily reflect long-term stored content that is used for archiving, preservation, and most notably reuse. Content management (CM), on the other hand, is the use of stored digital or media asset elements, retrieved and used for a specific time period.

\section{DEFINING THE ENTERPRISE}

We have not finished defining the environment at this point. There are two other key statements to be defined. Once we have determined these statements we can then define what our strategy will be as well as align the appropriate resources. The first - what is an "enterprise?" Again loosely used by individuals and companies it is important to define the enterprise. An enterprise may be a corporate entity with reporting divisions and/or business units. Another example may be just the division and even a third could be defined as a local office or even in some cases a 


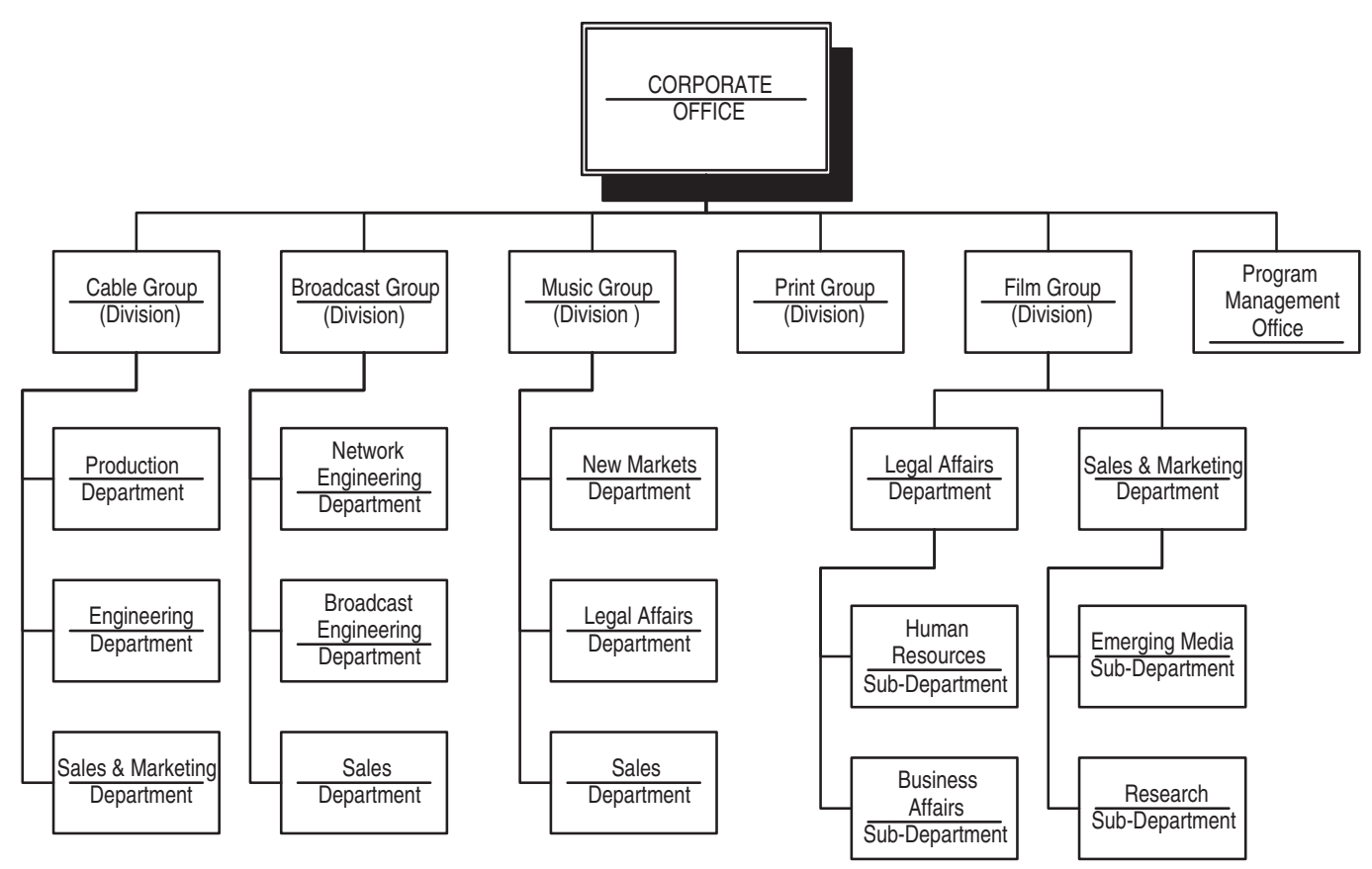

Figure 1: Sample enterprise structure

department. Confusing? Each use of the word enterprise is correct in all three examples, the definition of your enterprise. In the case of communication it is very important to set the expectations correctly for your organization, your team members, and your business partners. An enterprise is the encompassing body in its entirety. There may be groups within the enterprise, divisions or business units within the groups, and departments within the division. Still you may have departments that have subdepartments, eg legal affairs may encompass human resources, legal affairs, and business affairs.

It is important to set the appropriate expectation for what your particular enterprise encompasses; this will become more apparent later in the paper (see Figure 1).

\section{ACCOUNTING PRINCIPLES: IMPORTANT OR NOT?}

It is important to understand your accounting methods. How will you account for any or all of the three asset management initiatives indicated above? Not only is it important to define your return on investment (ROI), but which entity will fund what, when, and how? Does your corporate office support and fund your infrastructure? Does this body handle things such as communications, financial and email systems, storage, and data centers? Dependent upon your answers you can reduce cycle times in your research, financial due diligence, architecture, and deployment. As previously mentioned, one of the components of a DAM strategy is reduced cycle times - you are already on your way by understanding how these initiatives may be accounted for. Not only in how you may account for the initiative but to what scale.

Remember, your decision of which asset

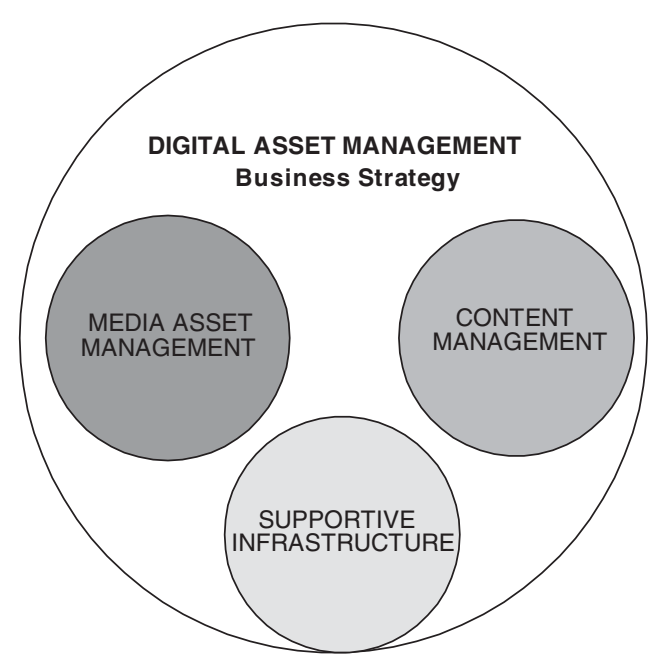

Figure 2: Components of the DAM strategy 
management play, its enterprise, how it will be financially monitored and managed are all keys to launching the right strategic initiatives (see Figure 2).

With respect to any industry, all asset management initiatives may be in use for a particular purpose, within the same organization or possibly across divisional lines.

\section{SET THE BASELINE FOR THE ASSET STRATEGY}

It is extremely important to understand your true strategy from the beginning. The mismanagement of initiatives and projects is well documented. How they take longer and cost more than expected, and even upon delivering the proposed solution whether it launched correctly and fulfilled the customer's expectations. Not only is it important that the customer received what they expected, but what did the initiative's sponsor receive?

There are many reasons why an initiative fails, but the base issue is usually communication and interpretation. What are the specific guidelines for the strategy? In a three-tiered method you can state that strategies are set, initiatives are launched under the umbrella of the strategy, and multiple projects will be executed under the specific initiatives (see Figure 3).
If you set the appropriate baseline for each one of the levels above you can greatly reduce your risk in having an initiative or project extend further than originally expected.

\section{DETERMINING THE APPROPRIATE ASSET STRATEGY}

You may determine your strategy by asking yourself a few standard questions. This will help in a number of ways. Your answers will set the baseline for what your strategy, initiative or project expectations should be. The output can drive the research into what products or services may be required, what your risk level may be, and what avenues for funding are appropriate. As an exercise, ask yourself a few questions to determine the definition of your asset strategy - as an example, we will also answer these here.

Q: Which group or individual is launching the strategy?

A: The corporate technology board.

Q: Which entity(ies) are funding the initiative?

A: The corporate office will fund the overall strategy and have responsibility for the roll-up of the ROI; however, the divisional office will be required to meet its own projected ROI based upon an internal rate of return (IRR).

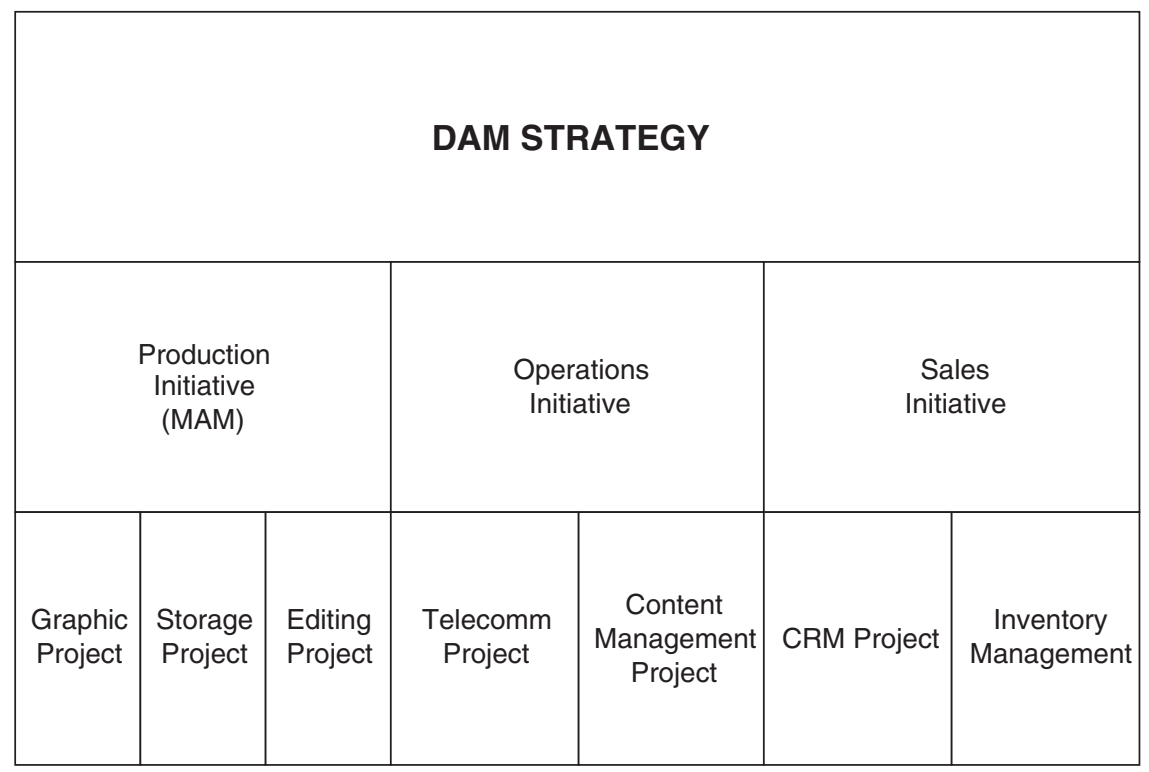

Figure 3: Guidelines for the structure of the DAM strategy 
Q: Is there a centralized body to manage the infrastructure?

A: Yes. The corporate "Managed Services or Operations Group" team will be responsible for managing the infrastructure. This includes data centers, server pools, telecommunications, email, and device administration.

Q: Is this an enterprise-wide, divisional or departmental strategy?

A: Divisional. My enterprise encompasses a single division. As the economic and financial

environment evolves future divisions may launch in the same fashion.

Q: Will this strategy encompass only rich media or all digital data?

A: This will be a digital asset management strategy that will be launched in phases within departments, within the division.
From these short questions and answers we are able to set a baseline for the strategy. First, this is a digital asset management strategy. The target will be to focus specifically on a particular division, with a phased departmental approach. Infrastructure guidelines and policies already set by the corporate operations group will help in the procurement of computer equipment and services needed for the overall solution. The division will require a complete financial study and be held responsible for managing the budget and return.

\section{THE BASELINE HAS BEEN SET}

We have now determined our baseline by answering the few questions above. Now what? First, it is crucial to communicate specifically what the initiatives will be under the strategy
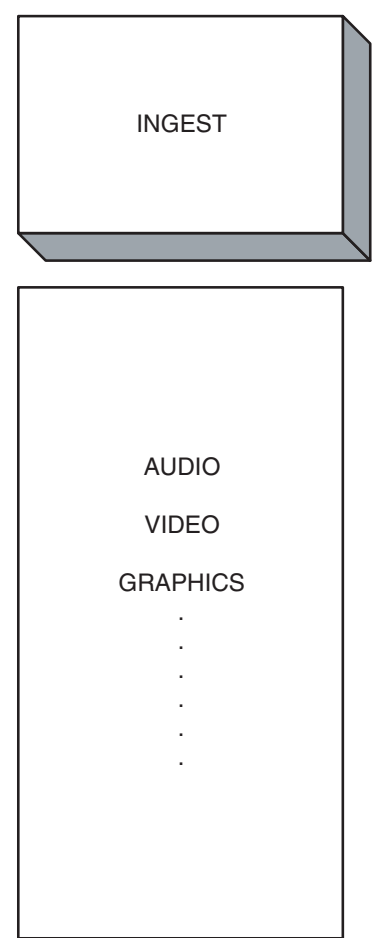
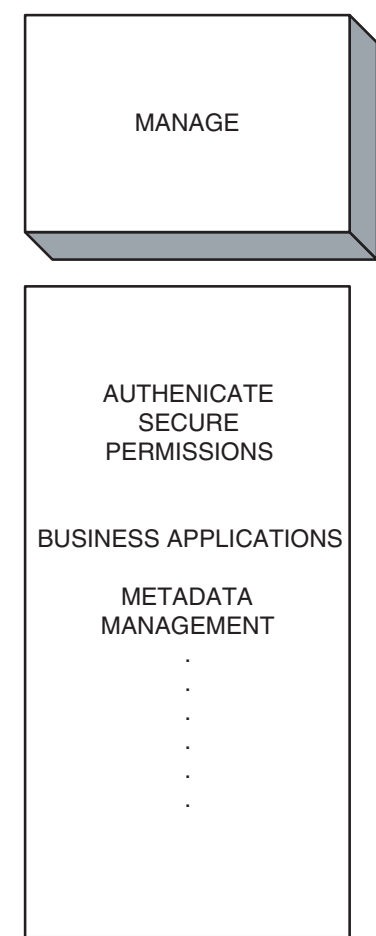
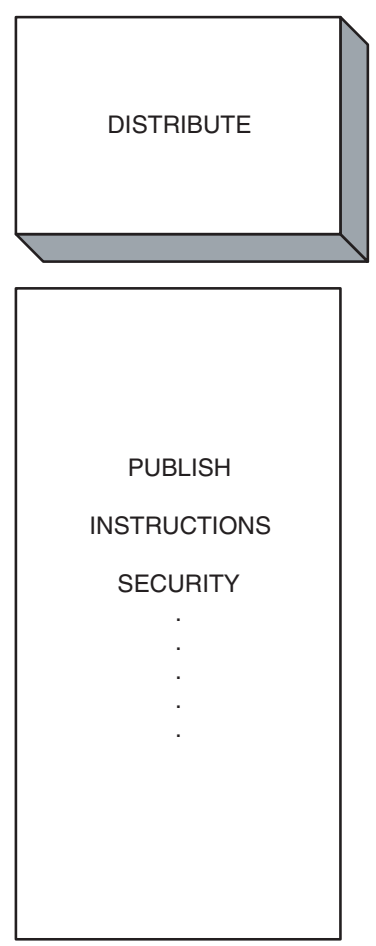

INFRASTRUCTURE (DATA CENTERS, TELECOMM, STORAGE, SERVERS ...)

Figure 4: Sample DAM strategy 
that has been set by executive management. In our example we have three large-scale initiatives under the DAM strategy: production, operations, and sales. This information needs to be communicated to all parties involved. The team responsible for executing the due diligence has the responsibility for communicating or recommunicating with each department what the overall strategy entails and which initiatives will fall to their specific department. The exact projects at this time may not be defined, since the due diligence is not complete.

Now the initiatives are defined, first on the agenda is to interview key stakeholders for their input. What does the strategy mean to them? What goals do they want to achieve in the initiative? What are their business drivers? Once you have flushed out the business needs of the department and aligned them to the strategy set by executive management, you are ready to execute the financial research. This step will determine how you will move forward. Strategies are one thing - actually paying for them is another.

\section{A STRATEGIC SCENARIO}

Here follows a quick set of examples for each type of asset strategy. A long-term DAM strategy may be to share all types of digital asset metadata for financial, sales, production, tracking, or reporting purposes. MAM strategies may support this long-term DAM strategy by managing rich media (audio, video, graphics, etc) within a specific department, say production or graphic editing. A content management strategy may be to publish content for print or via a website for a specific time period. Overall, the DAM strategy will provide an umbrella to link departmental initiatives so that an organization may determine, view, and report how their assets are used and quantify their value.

In our DAM strategy example (see Figure 4), the goal is to tie the rich media assets (video, audio, and graphics) to the business applications (sales, contracts, financials) that support the company goals and directions. Architecturally, these systems are quite different, yet have the same targeted goal, to increase workflow efficiencies, facilitate intra-departmental communication, and leverage existing assets. The architecture should focus on the sharing of metadata, therefore reducing redundant data entry and providing the ability to view the enterprise through a comprehensive user interface. The utilization of the metadata is the focus and during design stages it will be crucial to ensure all applications may be linked via these metadata keys in order to support the ability to drill into the various systems to achieve this strategic view.

In our example we also have an initiative to provide a MAM architecture to support the production department. This initiative will support the ingest and management of rich video, audio, and graphical content. There are a number of projects that will evolve from this initiative. Such projects may be related to storage and storage management, ingest and editing tools, metadata management and so on. Additionally, in our example we are supporting the operations department with a content management solution which will drive shortterm distribution needs. This initiative will utilize the master digital asset repository in conjunction with the production MAM. Together they will provide the necessary video, audio, graphics, text, and metadata which will allow the content management system to extract what is needed to support the websites and will "live" in the system for a short period of time.

\section{THE END GAME - “THE EVENT"}

By building a modular, departmental MAM suite of applications, the DAM strategy will be tied together to provide a complete view of the business environment. The value? An executive can search for an asset, view it, query on who produced it, what the contract represented, what the financial aspects were, when the marketing launch occurred, what was the return, and so on. The strategic target is to provide the ability to search, locate, distribute, and report, via a comprehensive view, any and all information related to a particular event. The tactical approach will lead to a reduction in inefficiencies and costs while increasing revenue through better management and reporting. Additionally, you will be truly able to track the costs for the event and its return, all the while gaining a thorough understanding of the value of each asset. This in turn will support your financial reporting both internally and externally. This is not brain surgery but very good, very hard work. 
However an organization may approach the asset management strategy, there are ways in which to gain a head start and that is by applying products that are integrated before they are implemented. Additionally, an organization should ensure that it has engaged the right resources to design a scalable and extendable architecture and that all nuances of the financial investments will be recoverable, which will lead to tangible efficiency gains and increased revenues.

As previously mentioned, the architectures to support these various asset initiatives are similar but have nuances that drive strategic partnerships, product acquisition, and development. Some organizations, like our example, have operations groups that support the infrastructure, which can help with the acquisition of product and services. They may have set standards such as specific storage suppliers, database tool sets, web and web application servers. They in turn have developed the skill sets and provide resources to help with the installation and support of such services. This can certainly help in the overall process as additional research and business cycles may be saved as the standards for the business have already been set.

Keeping to the "ABCs" of asset management, there are three basic principles to remember: ingest, manage, and distribute. In any environment, you will be able to define both technologically and financially services that will fall within one of these three areas - our forthcoming paper in a future issue of the Journal will discuss how to align the ingest, manage, and distribute model to your initiatives. 